\title{
Pemetaan Gua Kalibbong Aloa Kawasan Karst Pangkep
}

\section{Mapping of Kalibbong Aloa Cave Karst Pangkep Area}

\author{
$\left.\mathrm{Uca}^{1}\right)^{*}$, Ria Angriani ${ }^{2)}$ \\ ${ }^{1,2)}$ Jurusan Geografi, Universitas Negeri Makassar
}

Received 30 ${ }^{\text {th }}$ March $2018 /$ Accepted $27^{\text {th }}$ June 2018

\begin{abstract}
ABSTRAK
Pemetaan gua merupakan salah satu upaya untuk mendokumentasikan gua, sehingga peta akan menjadi informasi untuk penelusur gua, penulusur akan mengetahui bentuk gua, ukuran, ornamen yang menghiasi, jauh dari sebelum memasuki gua.Penelitian ini bertujuan untuk mengetahui morfometri gua Kallibong Alloa kawasan Karst Pangkep. Penelitian ini menggunakan jenis penelitin deskriptif dan pengumpulan data dilakukan dengan teknik observasi, dokumentasi, pengukuran lapangan denganvariabel tinggi atap gua, lebar loro ng gua, panjang gua, arah lorong gua, kemiringan gua, dan ornamen gua. Data yang diperoleh berupa peta morfometri Gua Kalibbong Aloa yang diolah menggunakan software Compass Cave dan Corel DrawX7. Hasil penelitian menunjukkan bahwa Gua Kalibbong Aloa memiliki panjang 340.52 meter dengan entrance (mulut gua) yang mengarah ke arah $85^{\circ}$ (timur) yang berukuran lebar 7.1 meter dan tinggi 3 meter, rerata kemiringan 9.00 . Adapun ornamen yang ditemukan yaitu stalaktit, stalakmit, flowstone, pearl, helectit, pilar, dan Gorden.
\end{abstract}

Kata kunci: Pemetaan gua, Morfometri, Kawasan Karst, Kabupaten Pangkep.

\begin{abstract}
Mapping the cave is one effort to document the cave, so the map will be the information for caveman, the caveman will know the form of cave, size, ornaments that adorn, far from before entering the cave.This research aims to know the morphometry of Kallibong Alloa cave Karst Pangkep area. This research uses descriptive research type and data collection is done by observation technique, documentation, field measurement with high variable of cave roof, cave alley width, cave length, cave alley direction, cave slope, and cave ornament. The data obtained in the form of morphometry map of Kalibbong Aloa Cave is processed using Compass Cave and Corel DrawX7 software. The results showed that Kalibbong Aloa Cave has a length of 340.52 meters with entrance (cave mouth) which leads to $85^{\circ}$ (east) which measuring 7.1 meters wide and 3 meter high, $9.00^{\circ}$ slope average. The ornaments that found are stalactites, stalagmite, flowstone, pearl, helectit, pillars, and curtains.
\end{abstract}

Keywords: Cave Mapping, Morphometry, Karst Area, Pangkep District.

*Korespondensi:

email: ucasideng@yahoo.com 


\section{PENDAHULUAN}

Bentang lahan karst adalah suatu bentang alam yang dibentuk oleh batu gamping. Bentang lahan karst juga merupakan daerah resapan air. Topografi bentang lahan karst dapat berupa cekungan-cekungan, kubah-kubah serta gua kapur. Topografi bentang lahan karst dapat dengan mudah dikenali berdasarkan morfologi yang spesifik tersebut (Kasri N 1999).

Dalam morfologi karst terdapat dua buah bentukan, yaitu eksokars dan endokars. Eksokars merupakan bentuk morfologi topografi wilayah karst yang berada dipermukaan. Sedangkan endokarst merupakan bentukan-bentuk morfologi relief karst yang berada dibawah permukaan (Wardani Putri 2008).

Gua merupakan salah satu contoh dari morfologi endokarst. Gua merupakan sebuah bentukan alami berupa ruangan karst yang terbentuk pada medan batu gamping dibawah tanah baik yang berdiri sendiri maupun saling terhubung dengan ruangan-ruangan lain sebagai hasil proses pelarutan oleh air maupun aktivitas geologi yang terjadi pada suatu daerah.

Gua dapat dikembangkan menjadi berbagai macam pemanfaatan seperti wisata, penyimpanan air, pertambangan, dan habitat makhluk hidup. Olehnya itu, gua merupakan salah satu asset yang harus di data. Ketersediaan GIS dan peta sangat penting untuk menentukan pemanfaatan yang tepat bagi gua tertentu.

Pemetaan sebuah gua merupakan salah satu upaya untuk mendokumentasi kan gua, sehingga peta akan menjadi informasi untuk penelusur gua lainnya. Peta memberikan deskripsi mengenai gua, ukuran, ornamen yang menghiasi. Peta mampu menjadi alat atau sumber informasi sebelum memasuki gua tertentu. Pemetaan juga memberikan informasi ilmiah yang berguna bagi penelitian ilmu pengetahuan. Peta gua juga berarti sebagai bukti seorang caver telah memasuki atau mengeksplorasi suatu gua.

Di kawasn karst Maros- pangkep sendiri sedikitnya, jumlah gua yang disurvei dalam kegiatan identifikasi pemetaan sebaran gua alam di Taman Nasional bantimurung Bulusaraung khususnya wilayah Resort Bantimurung dan Resort Pattunuang Karaenta yaitu sebanyak 89 gua, 55 gua diantaranya belum pernah terdata sebelumnya. Gua tersebut mempunyai berbagai macam bentuk, ukuran dan panjang lorong. Letak mulut gua pun ada yang diatas tebing, pada dasar dinding tebing, ataupun di permukaan tanah secara vertical.(Balai Taman Nasional Bantimurung Bulusaraung. 2010).

Potensi dari setiap gua alam yang ada sangat besar, berupa dekorasi, dekorasi yang ada dalam gua, seperti stalakmit, stalaktit dan pilar. Salah satu gua yang menarik untuk diteliti adalah gua Kalibbong Aloa. Berdasarkan hasil observasi gua Kalibbong Aloa memiliki banyak bentukan-bentukan dalam gua yang indah menarik seperti stalaktit, stalakmit, danau, dinding-dinding gua yang dihiasi dengan kilau Kristal-kristal CaCo3, namun demikian belum ada informasi mengenai kondisi gua (morfometri gua), oleh karena itu perlu di eksplorasi dan di petakan. 


\section{METODE PENELITIAN}

Jenis penelitian yang digunakan dalam penelitian ini berdasarkan dengan cara tau taraf pembahasannya termasuk jenis penelitian deskriptif yang bertujuan untuk mendiskripsikan atau menggambarkan obyek dalam penelitian.Penelitian ini mengkaji beberapa variable, yaitu Morfometri Gua : Tinggi atap gua, Lebar lorong gua, Panjang gua, Arah lorong gua, Kemiringan gua, jenis dan sebaran ornamen-ornamen gua.

Alat dan bahan yang digunakan dalam penelitian ini meliputi perlatan dan bahan untuk survey lapangan : Global position Sistem (GPS) Garmin, Clinometer Sunto, Tripod untuk menempatkan piringan sudut, Program compass cave, Corel Draw, ArcGIS dab Global Mapper, Headlamp, Kamera untuk dekomentasi, Laser Distance Makita LD050P, Mistar Bak sebagai tiang titik stasiun untuk mengukur kemiringan

Teknik Pengumpulan Data : dalam pengukuran dilapangan, teknik yang akan digunakan adalah forward method yaitu pembaca alat dan pencatat berada pada stasiun 1 (pertama) dan pointer (target) berada pada stasiun 2 (kedua), setelah pembacaan alat selesai pointer maju ke stasiun selanjutnya yang telah ditentukan oleh leader dan pembaca alat maju tepat pada posisi pointer tanpa merubah titik stasiun tempat berdiri pointer sebelumnya, begitu seterusnya. Survey grid yang digunakan 6D (BCRA).

Suatu tempat dapat dijadikan stasiun survei apabila memenuhi salah satu dari syarat yaitu :

a. Mewakili perubahan lebar lorong, misalnya pada awal penyempitan atau pelebaran

b. Mewakili perubahan tinggi atap, stasiun ditempatkan dibawah bagian atap yang mewakili perubahan ketinngian atap.

c. Mewakili perubahan arah lorong

d. Mewakili perubahan kemiringan lantai

e. Mewakili perubahan pada kondisi dan situasi lorong, termasuk didalamya perubahan sedimen dan jenis ornament.

f. Berada pada posisi yang dapat berperan sebagai titik ikat bagi percabangan lorong

g. Berada pada jarak tidak lebih dari 30 meter dari stasiun sebelumnya.

Untuk mengukur chamber atau aula gua, teknik yang akan digunakan adalah offset method yaitu mengukur jarak ke dinding kiri dan kanan dari stasiun yang ditentukan di dalam chamber/aula (Erlangga 2016).

Analisis Data :Pengolahan data menggunakan software Compass Cave, ArcGIS, Global Mapper danCorel Draw X7

\section{HASIL DAN PEMBAHASAN}

\section{Gambaran umum lokasi penelitian}

Kelurahan Biraeng merupakan salah satu kelurahan yang ada di Kecamatan Minasa Te'ne Kabupaten Pangkep. Lokasi penelitian ini terletak di Kelurahan Biraeng. Di Kelurahan Biraeng terdapat sebuah gua yang bernama Gua Kablibong Aloa yang terletak $4^{\circ} 50^{\prime} 35.75^{\prime}$ ' S dan $119^{\circ} 37^{\prime} 0.43^{\prime}$ '. Gua ini merupakan lokasi penelitian, terletak di 
tengah perbukitan karstsehingga sangat sulit untuk mencapainya, dibutuhkan keahlian, pengalaman, mental, dan perlengkapan caving dan climbing yang memadai. Karena di antara medannya ada yang terjal atau berada di kemiringan 90 derajat. Karst landscape di kawasan ini antara lain dataran tinggi, kebun, sawah, perbukitan, lembah terjal. Secara geografis Kelurahan Biraeng berbatasan dengan sebelah utara dengan kelurahan Kalabbirang, sebelah barat berbatasan dengan Kecamatan Pangkajene, sebelah timur berbatasan dengan kelurahan Kalabbirang, sebelah selatan berbatasan dengan Kelurahan Kabba dan Kelurahan Panaikang.

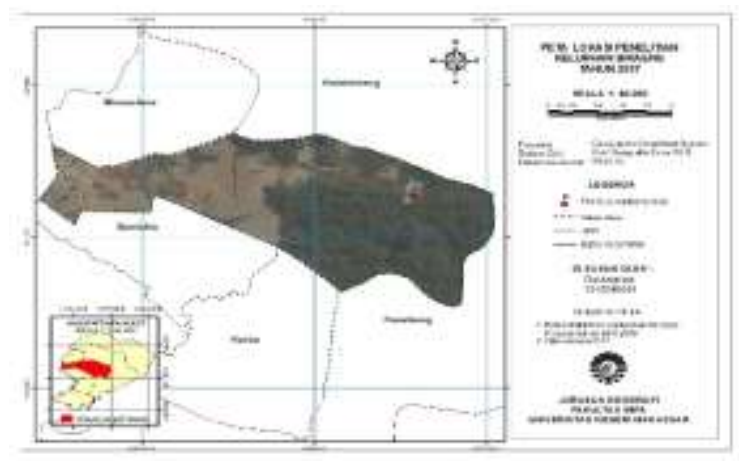

\section{Hasil}

Tabel 1. Kondisi fisik lorong Gua Kalibbong Aloa

\begin{tabular}{|c|c|c|c|c|c|c|c|}
\hline \multirow[b]{2}{*}{ Aula/lorong } & \multirow[b]{2}{*}{ Stasiun } & \multirow[b]{2}{*}{ Panjang } & \multicolumn{2}{|c|}{ Rata-rata } & \multirow{2}{*}{$\begin{array}{c}\text { Luas } \\
\text { penampang } \\
(\mathbf{m} 2)\end{array}$} & \multirow{2}{*}{$\begin{array}{c}\text { Kemiringan } \\
\left({ }^{\circ}\right)\end{array}$} & \multirow{2}{*}{$\begin{array}{c}\text { Tipe } \\
\text { jatuhnya } \\
\text { air } \\
\end{array}$} \\
\hline & & & $\begin{array}{c}\text { Lebar } \\
(\mathbf{m})\end{array}$ & $\begin{array}{l}\text { Tinggi } \\
\text { (m) }\end{array}$ & & & \\
\hline ALI & $0-3$ & 10.21 & 9.64 & 2.7 & 26.02 & -10.33 & - \\
\hline LRI & $3-11$ & 31.85 & 4.09 & 3.52 & 14.39 & 15.37 & - \\
\hline ALII & $11-14$ & 11.69 & 12.97 & 7.02 & 91.04 & 37.66 & Tetesan \\
\hline ALIII & $14-17$ & 19.65 & 9.51 & 10.89 & 103.56 & 2.75 & Tetesan \\
\hline LRII & $18-21$ & 11.18 & 3.01 & 7.93 & 23.86 & 1.66 & Tetesan \\
\hline ALIV & $21-27$ & 21.51 & 7.48 & 8.26 & 61.78 & 7.83 & Tetesan \\
\hline AL V & $27-31$ & 17.12 & 6.71 & 6.29 & 42.20 & 2.25 & - \\
\hline AL VI & $31-36$ & 29.37 & 11.85 & 4.92 & 58.30 & 4.6 & - \\
\hline AL VII & $36-41$ & 27.73 & 16.01 & 5.95 & 95.25 & 2.6 & Tetesan \\
\hline LR III & $41-45$ & 19.54 & 8.57 & 2.86 & 24.51 & 6 & Tetesan \\
\hline AL VIII & $45-48$ & 23.9 & 14.59 & 9.08 & 132.47 & 4 & Rembesan \\
\hline LR IV & $48-50$ & 13.74 & 3.06 & 7.6 & 23.25 & 3.5 & Tetesan \\
\hline AL IX & $50-54$ & 25.59 & 8.34 & 4.42 & 36.86 & 5.75 & Tetesan \\
\hline LR V & $54-56$ & 8.75 & 3.04 & 2.42 & 7.35 & -7 & - \\
\hline AULA X & $56-62$ & 28.76 & 15.27 & 5.72 & 87.34 & 13 & Tetesan \\
\hline LR VI & $62-64$ & 11.32 & 10.12 & 6.79 & 68.71 & 15.5 & Tetesan \\
\hline AL XI & 64-69 & 28.61 & 14.41 & 6.85 & 98.70 & 13.25 & - \\
\hline
\end{tabular}

Sumber : pengolahan data. 2017

Ket $: \mathrm{AL}=$ Aula $\mathrm{LR}=$ Lorong $(-)=$ mengalami penurunan lantai 
Dari hasil pengukuran morfometri Gua Kalibbong Aloa, didapatkan jumlah stasiun sepanjang lorong gua yaitu 68 stasiun. Dengan stasiun terpanjang berada di stasiun 35 36 dengan panjang 13.12 meter, kedua berada pada stasiun 3-4 dengan panjang 12.03 meter, dan jarak yang paling terpendek ada pada stasiun 6-7 yaitu 1.2 meter. Perubahan kemiringan lantai gua paling besar terdapat di stasiun 12-13 dengan kemiringan $-33^{\circ}$ dan pada stasiun 62-63 dengan kemiringan $31^{\circ}$ dimana tanda (-) menunjukkan lantai mengalami penurunan, sebaliknya jika tidak menggunakan tanda (-) menunjukkan kenaikan lantai gua (tanjakan). Di lihat dari tabel diatas terdapat enam jenis ornament yang tersebar sepanjang lorong gua yaitu stalaktit, stalakmit, pilar, helectit, pearl, gorden, dan flowstone. Ornament yang paling mendominan yaitu stalaktit dan stalakmit.

Berdasarkan hasil pengamatan dan pengolahan data pengukuran pada Gua Kalibbong Aloa, maka dapat diperoleh gambaran dari morfometri gua. Gua Kalibbong Aloa memiliki 11 chamber (aula) dan 6 lorong yang menghubungkan tiap chamber (aula) yang merupakan hasil dari pengamatan dan pengukuran langsung di lapangan.

Dilihat dari tabel di atas Aula VIII merupakan aula paling luas dibanding dengan aula lainnya yaitu $132.47 \mathrm{~m} 2$ dari stasiun 45-48 dengan panjang 23.9 meter dan kemiringan $4^{\circ}$. Bagian yang memiliki luas penampang terkecil ada pada lorong I dengan luas 14.39 dari stasiun 3-11 stasiun dengan panjang 31.85 meter dan kemiringan $15.37^{\circ}$.

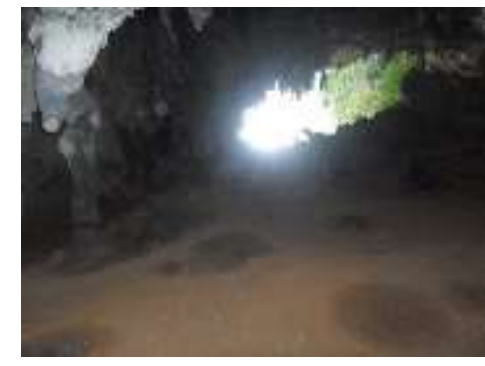

(a). aula I

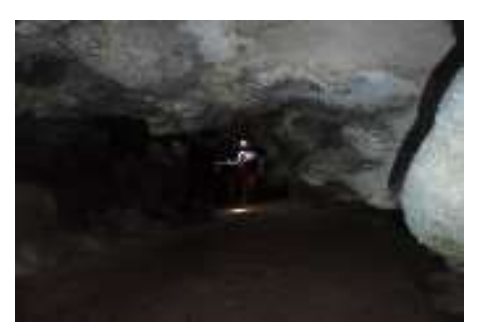

(d). lorong $I V$

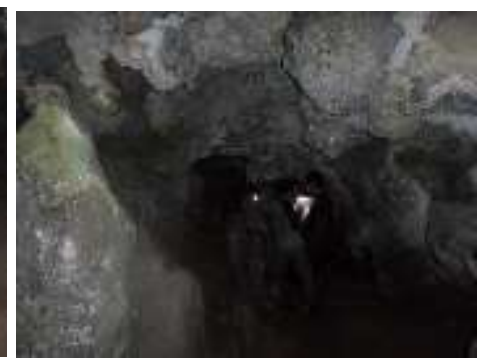

(b). Lorong II

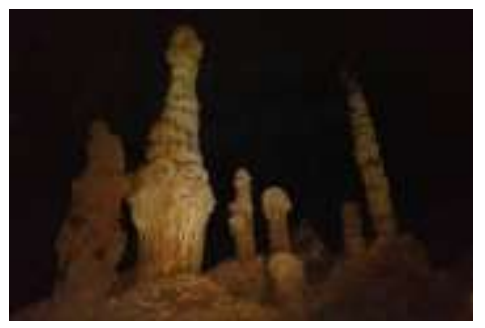

(e).stalakmit

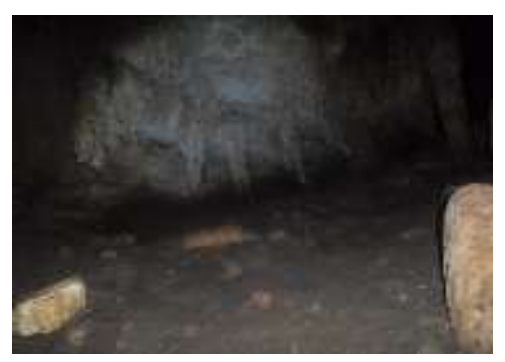

(c). aula III

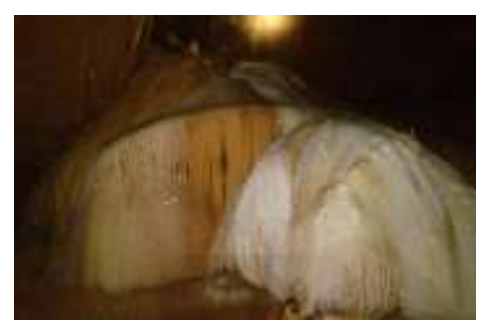

(f). flowstone

Sumber : Data Lapangan, 2017

Gambar 1. kondisi gua Kalibbong Aloa 
Tabel 2. Profil Gua di Kawasan Karst Pangkep

\begin{tabular}{cccccc}
\hline \multirow{2}{*}{ Nama Gua } & $\begin{array}{c}\text { Panjang } \\
\text { Gua } \\
(\mathbf{m})\end{array}$ & $\begin{array}{c}\text { Lebar } \\
\text { Lorong } \\
(\mathbf{m})\end{array}$ & $\begin{array}{c}\text { Tinggi } \\
\text { atap } \\
(\mathbf{m})\end{array}$ & $\begin{array}{c}\text { Kemiringan } \\
\left({ }^{\circ}\right)\end{array}$ & Tipe Gua \\
\hline $\begin{array}{c}\text { Kalibbong } \\
\text { Aloa }\end{array}$ & 340.52 & 9.33 & 6.07 & 9.00 & Horisontal \\
\hline
\end{tabular}

Sumber : pengolahan data. 2017

Dari tabel diatas menunjukkn Gua Kalibbong Aloa merupakan gua dengan tipe horizontal memiliki panjang 340.52 meter dengan rata-rata lebar lorong 9.33, tinggi atap 6.07 meter, dan kemiringan9.00 . Gua Kalibbong Aloa memiliki mulut pada ketinggian $755 \mathrm{~m}$ dpl dengan atap mulut gua setinggi 3.1 meter dan lebar 4.10 meter.

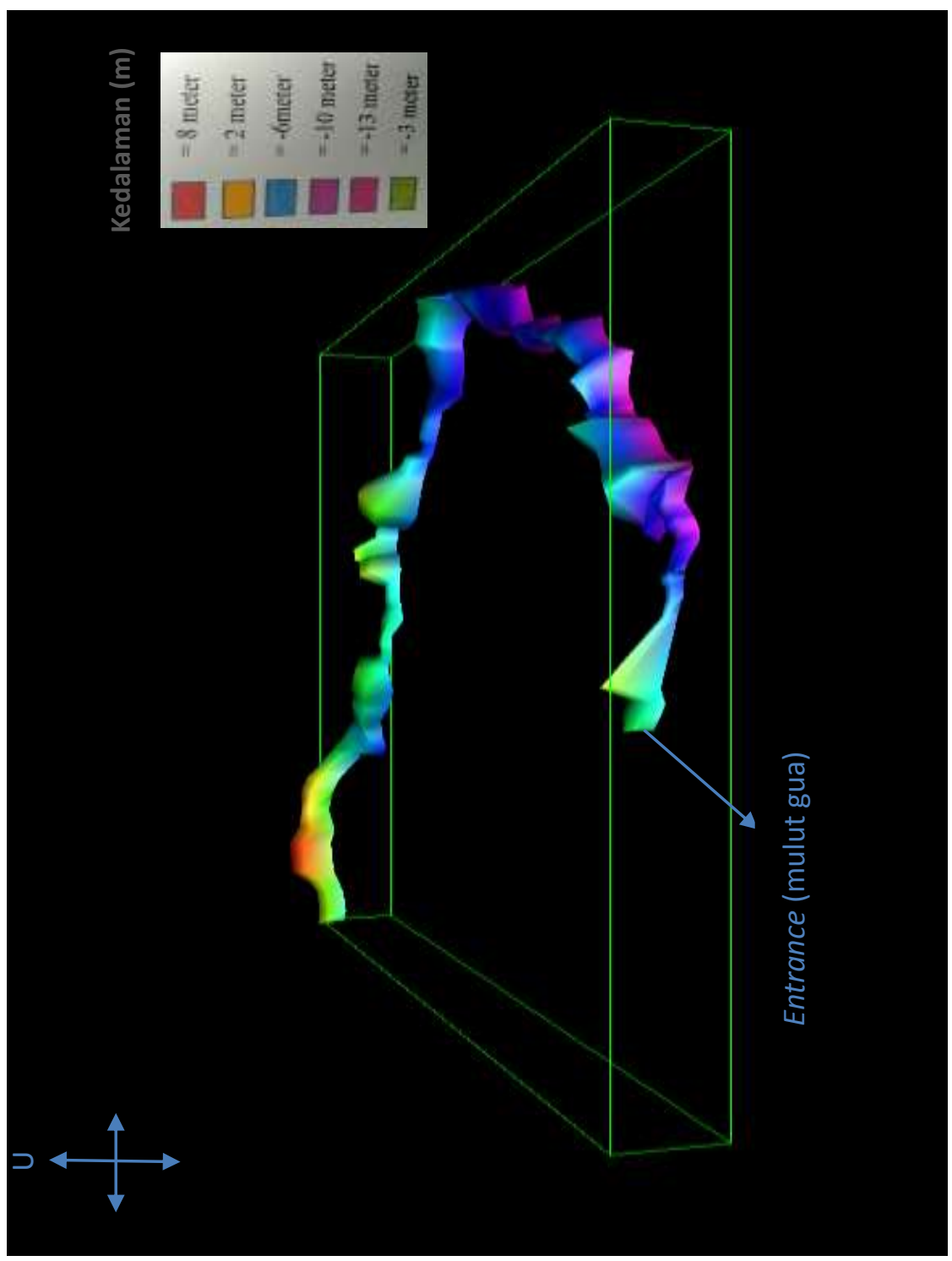

Gambar 2. 3D gua Kalibbong Aloa 


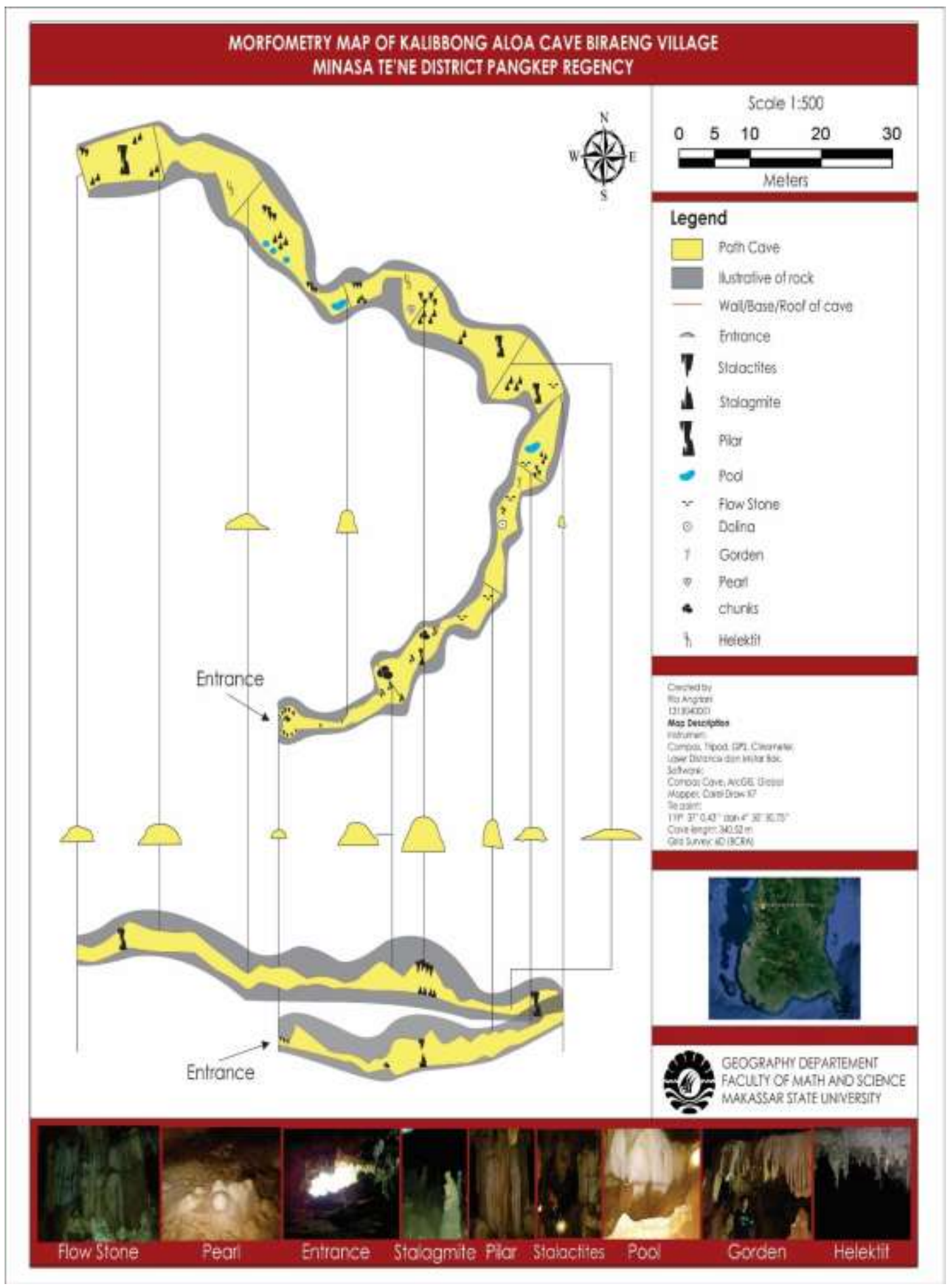

Gambar 3. Peta Morfometri gua Kalibbong Aloa 


\section{Pembahasan}

Myloire dan Carew (2003) membedakan gua yang terbentuk di daerah berbatuan karbonat menjadi tiga macam yaitu pit cave, phreatic cave, dan fracture cave. Berdasarkan klasifikasi tersebut, Gua Kalibbong Aloa bertipe phreatic cave dengan ciri mulut gua lebar denga kedudukan horizontal, terbentuk karena terjadi pelarutan batu gamping oleh aliran air tanah.

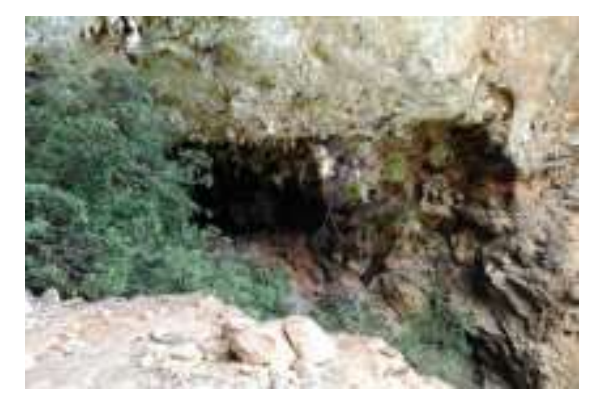

Gambar 4. Mulut Gua Kalibbong Aloa

Gua Kalibbong Aloa memiliki panjang lorong 340.52 meter dengan jumlah 69 stasiun. Dari 69 stasiun ada beberapa di titik stasiun memiliki panjang yang lebih di banding dengan jarak stasiun dengan stasiun lainnya. Stasiun 35-36 dengan panjang 13.12 meter, stasiun 3-4 dengan panjang 12.03 meter. Jarak stasiun dari 35-36 merupakan stsiun yang memiliki jarak terpanjang dari stasiun-stasiun yang lainnya ini di karenakan lantai gua yang datar, tdk adanya ornament yang mengahalangi pengukuran jarak antar stasiun sehingga memiliki jarak 13.12 meter begitupun dengan stasiun 3-4. Untuk stasiun dengan jarak terpendek yaitu stasiun 6-7 dengan panjang 1.2 meter ini di karenakan adanya bongkahan akibat runtuhan (breakdown) yan $g$ mengahalangi pengambilan data jarak di satsiun tersebut. Runtuhan (breakdown) banyak dijumpai dengan berbagai ukuran yang menunjukkan lemahnya perlapisan batu gamping.

Lorong gua kalibbong Aloa menunjukkan pola lorong sederhana dengan hanya memiliki satu lorong utama terlihat pada gambar 4.5. Palmer (1991) memberikan istilah single-passage caves untuk gua semacam ini .Lorong tunggal pada pada gua Kalibbong Aloa memiliki variasi di segmen lorong, yakni memiliki 11 chamber (aula) aula dan 6 lorong yang menghubungkan tiap-tiap chamber (aula). Menurut palmer (1991) singlepassage caves adalah bentuk permulaan yang dalam perkembangannya dapat berubah menjadi berbagai pola lainnya. Aula VIII merupakan bagian terbesar dari seluruh bagian gua yang diamati dengan bentuk seperti ruangan (chamber) yang besar karena memiliki lebar lorong 14.59 meter dengan luas penampang yaitu $132.47 \mathrm{~m} 2$. Pembentukan dan perkembangan gua di pengaruhi oleh berbagai macam factor. Bahkan morfologi gua yang terbentuk merupakan hasil kombinasi kerja berbagai factor. Gillieson (1996) menyebutkan beberapa factor yamg mempengaruhi speleogenesis yaitu struktur geologi, litologi, kondisi kimia, kondisi hidrologi dan waktu. struktur geologi, litologi, kondisi kimia merupakan factor yang berpengaruh pada stasiun awal pembentukan gua, 
sedangkan kondisi hidrologi, iklim dan waktu pengaruhnya nampak dalam perkembangan gua selanjutnya.

Aula VIII paling luas bagian lorong tersebut mengandung $\mathrm{CaCO} 3$ tinggi akan mudah larut di banding dengan aula lain, air cenderung bergerak ketempat yang lebih rendah. Aula ini termasuk bagian lorong yang rendah. Ukuran besarnya gua tidak hanya tergantung pada intensitas proses kimiawi dan pengikisan yang berlangsung, akan tetapi juga ditentukan oleh jangka waktu proses itu berlangsung. Di samping itu terjadi runtuhan yang menambah luas lorong gua.

Lorong I dengan luas 14.39 dari stasiun 3-11 stasiun dengan panjang 31.85 meter bagian lorong gua terkecil di karenaka bagian lorong ini mengandung $\mathrm{CaCO} 3$ rendah sehingga pelarutan yang terjadi hanya melarutkan pada bagian lorong yang mengandung $\mathrm{CaCO} 3$ tinggi. Hal ini diakibatkan oleh tingginya tingkat kompaksi dinding sehingga sukar dilarutkan oleh air. Berdasarkan peta morfometri gua pada gambar 4.5 dengan pengamatan extended view (tampak atas bawah) di ketahui terjadi penurunan lantai gua dan perubahan kemiringan paling besar berada pada stasiun 12-13. Adapun penuruanan tidak nampak signifikan tetapi pada bagian tersebut memiliki kemiringan yangb paling besar. Gambar 4.5 menunjukkan Gua Kalibbong Aloa memiliki kelokan yang lembut.. kelokan tersebut menurut Palmer (1991) merupakan salah satu control bidang perlapisann dan retakan terhadap perkembangan lorong gua. Adapun speleothem (ornament) yang dijumpai antara lain stalaktit, stalakmit, pilar, flowstone, helectit, gorden dan pearl. Runtuhan (breakdown) banyak dijumpai dengan berbagai ukuran yang menunjukkan lemahnya bidang perlapisan batu gamping.

\section{KESIMPULAN}

Berdasarkan hasil penelitian mengenai morfometri gua Kalibbong Aloa dapat disimpulkan hasil dari penelitian ini adalag gua Kalibbong Aloa merupakan gua dengan tipe horizontal dengan entrance (mulut gua) yang mengarah ke arah $85^{\circ}$ (timur) yang berukuran lebar 7.1 meter dan tinggi 3 meter, panjang lorong 340.52 meter, rata-rata kemiringan $9.00^{\circ}$ dan tinggi atap 6.62 meter. Selain itu gua ini juga mempunyai 11 chamber (aula). Ornamen yang dijumpai antara lain stalaktit, stalakmit, gorden, pilar, helectit, pearl, dan flowstone.

\section{DAFTAR PUSTAKA}

Aristiyanto MH. 2005. Introduksi Speleologi. http//www.Indocover.org. Diakses tanggal 28 Maret 2017.

Ashari Arif. 2013. Pola lorong gua dan speleogenesis pada system perguaan GesingJlamprong-Sinden karst Gunungsewu. Jurusan Pendidikan Geografi FIS UNY.

Arisa Bangun. 2017. https://cfcunesa.wordpress.com/proses-terbentuknya-goa-/. Diakses tanggal 11 Maret 2017. 
Balai Taman Nasional Bantimurung Bulusaraung. 2010. http//www.tn-babul.org. Diakses tanggal 20 Maret 2017.

Gema. 2004. Sejarah Penelusuran Gua. Pecinta Alam Universitas Katolik-St Thomas Sumatera Utara. http//www.highcamp.web.id/file/artikelanda/file02.htm. Diakses tanggal 28 Februari Maret 2017.

Gillieson. 1996. Caves Proces Development and Mangement. Cambridge: Blacwell Publisher.

Handayani, A. 2009. Analisis potensi sungai bawah tanah di gua seropan dan gua semuluh untuk pendataan sumberdaya air kawasan karst di kecamatan Semanu Kabupaten Gunung Kidul Propinsi Daerah Istimewa Jogyakarta tahun 2007. Universitas Sebelas Maret.

IstikaWardhani, Putri. 2008. Morfometri ornament gua(Speleothem) di kawasan karst buniayu, sukabumi Jawa Barat. Departemen Geografi. Fakultas Matematika dan Ilmu pengetahuan Alam. Universitas Indonesia.

Kasri N, Tuti H. 1999. Kawasan Karst Indonesia: Potensi Dan Pengelolaan lingkunganya. Jakarta: Kantor menteri Negara Lingkungan hidup.

Laksamana Esa Erlangga. 2016. Teknik-teknik Pemetaan Gua Dan Survei Hidrologi Gua. Jogjakarta: Acintyacunyata Speleological Club.

Myloire, J.E. dan Carew, J.L. 2003 Karst Development on Carbonate Island. Speleogenesis and Karst Akuifer 1 (2): 1-21.

Mulyati Teti. 2007. Kajian Kondisi Gua Untuk Pengembangan Wisata Minat Khusus Di Kawasan Karst Gudawang Kabupaten Bogor. [Skripsi]. Bogor: Institut Pertanian Bogor.

Palmer, A.N. 1991. Origin and Morphology of Limestone Caves. Geological Society of America Bulletin 103: 1-21.

Samodra H. 2001. Nilai Strategi Kawasan Karst di Indonesia. Bandung: Pengelolaan dan Perlindungan Pusat Penelitian dan Pengembangan geologi.

Wibowo Setiabudi. 2016. Kondisi geologi dan speleology karst atetajawa. Yogyakarta.

William B. White, 1988. Sejarah Penelusuran Gua. Pecinta Alam Universitas Katolik-St Thomas Sumatera Utara. http//www.highcamp.web.id/file/artikelanda/file02.htm. Diakses tanggal 28 Februari Maret 2017. 